\title{
A MEMÓRIA LITERÁRIA E OS FOLHETINS PUBLICADOS EM RIO GRANDE
}

\section{RESUMO}

O presente artigo trata da importância da preservação do patrimônio cultural brasileiro, mais especificamente da memória literária conservada em acervos de arquivos públicos e privados, por meio da análise dos folhetins publicados em periódicos, na cidade de Rio Grande (RS), no decorrer do século XIX. Além disso, conceitua a propagação do gênero folhetim no Brasil e apresenta obras desconhecidas ou consideradas "desaparecidas" pela crítica e historiografia literária, centrando-se nas seguintes narrativas: Lúcia de Miranda (1851), de Candido Batista de Oliveira e Um drama no mar (1862), de Carlos von Koseritz.

Palavras-chave: folhetins, periódicos, patrimônio cultural.
Juliane Cardozo de Mello

Doutora em Letras pela FURG juliane.cdemello@gmail.com

\begin{abstract}
This article deals with the importance of preservation of cultural Brazilian patrimony, more specifically of the literary memory preserved in collections of public and private archives, through the analysis of serials published in periodicals, at Rio Grande (RS) city, during 19th century. In addition, it conceptualizes the propagation of the genre in Brazil and presents works unknown or considered "disappeared" by criticism and literary historiography, focusing the analysis on the following narratives: Lúcia de Miranda (1851), Candido Batista de Oliveira and Um drama no mar (1862), by Carlos von Koseritz.
\end{abstract}

Keywords: serials, periodicals, cultural patrimony.

\section{INTRODUÇÃO:}

Ao pensarmos na importância da preservação do patrimônio cultural brasileiro como forma de manutenção da memória da nação, surge-nos as questões concernentes às formas de conservação e ao acesso à informação. Para que a memória possa se perpetuar é preciso que as fontes documentais estejam resguardadas da ação do tempo e dos demais elementos 
que podem causar sua deterioração e, para isso, as mesmas devem pertencer a arquivos, públicos ou privados, que são "empreendimentos culturais direcionados a prolongar a vida útil dos objetos materiais e, assim, possibilitar a relação dialógica com estes bens culturais portadores de múltiplas significações" (CASTRO, 2008, p. 12).

O papel da memória é fundamental para a constituição de uma sociedade e, segundo Pereira, sua construção "está estreitamente vinculada ao acesso à informação, que por sua vez está vinculada à organização dos seus suportes materiais." (PEREIRA, 2011, p. 20). Dessa forma, não basta apenas que os documentos estejam protegidos, eles devem estar acessíveis à população, já que constituem a memória social de um determinado grupo de indivíduos, tanto a individual quanto a coletiva (PEREIRA, 2011, p. 24).

No que tange à literatura, o interesse pela preservação de acervos de diversos autores e as múltiplas pesquisas acerca das fontes primárias e secundárias são fundamentais para que obras do passado permaneçam acessíveis ao público. Ademais, esses estudos recuperam, muitas vezes, textos perdidos ou esquecidos pela crítica e historiografia.

A pesquisa em fontes documentais, em arquivos, em acervos particulares remete à busca de compreensão do passado e, com isso, da história. Ao pesquisarmos sobre uma determinada época, seguimos rastros, como afirma Paul Ricoeur:

Uma ação deixa um "rastro", põe sua "marca" quando contribui para a emergência de tais configurações que se tornam os documentos da ação humana. [...] Não se poderia dizer que a história constitui por si mesma o dossiê da ação humana? A história é esta quase "coisa" em que a ação humana deixa um rastro, põe a sua marca. Daí a possibilidade dos arquivos (RICOEUR, 1989, p. 195-196). 
A partir da ideia de rastros, podemos pensar que o estudo em periódicos do século XIX mostra-se um percurso salutar para a elucidação da formação da literatura no Brasil, com o aumento significativo de leitores e consumidores de poemas e textos ficcionais e de críticas literárias e teatrais.

O presente artigo tem como escopo os folhetins publicados nos jornais da cidade de Rio Grande (RS), polo político e econômico da Província no século XIX, no período de 1845 a 1889. A pesquisa, que descreveremos na sequência, foi realizada nos acervos da Biblioteca Rio-Grandense, primeira biblioteca do estado, que preservou a cultura letrada da região sul do Brasil.

\section{OS FOLHETINS:}

O ideário romântico e o folhetim surgem no Brasil, mais especificamente no Rio de Janeiro, após a abdicação de D. Pedro I e em meio às consequências políticas e econômicas que a recente independência causara ao Império. Grande parte dos movimentos políticos do período da Regência e do Segundo Reinado aproximava-se por um caráter democrático, antiportuguês e nacionalista. Entretanto, essa tendência nacionalista mostrava-se dividida no que tange à proposta política para a estruturação do país independente, já que a maioria das camadas populares, uma parte da classe média e alguns burgueses aprovavam a solução republicana e os senhores de engenho e do café, grandes proprietários rurais e os capitalistas eram favoráveis à ideia de um poder central forte - a Monarquia - posição que preponderou com a maioridade antecipada de D. Pedro II (TINHORÃO, 1994, p. 21). 
A imprensa brasileira começa a repercutir o gênero, em expansão na Europa, na década de 1830, com a publicação de Capitão Paulo, de Alexandre Dumas; sendo que "entre 1839 e 1842 os folhetins são praticamente cotidianos no Jornal do Comércio, embora os autores não sejam ainda os mais modernos" (MEYER, 2005, p. 283). Um dos introdutores do novo gênero foi Justiniano José da Rocha que, além de traduzir diversas obras francesas como, por exemplo, O Conde de Monte Cristo e Os miseráveis, foi autor de uma novela histórica, publicada na folha citada, em 1839, intitulada Os assassinos misteriosos ou $A$ paixão dos diamantes.

Todavia, é apenas na década de 1840 que os folhetins destacaram-se na imprensa, com a publicação de obras como Os Mistérios de Paris, de Eugène Sue. O fenômeno francês intitulado Rocambole, de Ponson du Terrail, irá ser publicado no mesmo jornal, com uma grande divulgação, a partir de 1859, com a republicação em 1870; ainda em relação aos autores franceses é possível salientar a presença de Xavier de Montépin, em 1879 e 1880.

Não se pode negar, então, a importância dos autores e da literatura francesa para a literatura brasileira. Meyer destaca, entre outros, o sucesso de Ponson du Terrail e José Ramos Tinhorão salienta Octave Feuillet. Inúmeros outros autores, representantes do gênero circularam no Rio de Janeiro e nas províncias no Oitocentos. As traduções dos folhetins, publicadas nas folhas de todo o Império, influenciaram os escritores a se aventurarem na escrita de obras que retratassem o Brasil: na esteira dos Mistérios, por exemplo, Mistérios da roça, Mistérios da Tijuca, Mistérios do Rio de Janeiro, Mistérios de Rio Grande, etc. 
Aos precursores brasileiros faltavam as técnicas narrativas, pois "mistérios, misérias, etc. se multiplicavam, sem que tenham o sal, o apelo e a tarimba dos modelões franceses, ainda que possam ocasionalmente reproduzir algumas de suas características" (MEYER, 2005 , p. 304). A leitura do folhetim francês propiciou, muitas vezes, aos escritores, o vislumbre de técnicas, temas, modelos, que serão fundamentais para a sua escrita.

Em Rio Grande, a importação de ficção foi intensa a partir da década de 1850 e muitos folhetins foram traduzidos e publicados nos jornais locais. As obras que compõem o corpus desta pesquisa foram localizadas nos seguintes periódicos, que compõem parte do acervo da Biblioteca Rio-Grandense: Rio-Grandense (1845-1854), A Imprensa (1855), Novo Rio-Grandense (1858-1859), Diário do Rio Grande (1861-1889), Eco do Sul (1858-1885), Inúbia (1868), Arcádia (1870), O Tempo (1871-1872), Gazeta Mercantil (1879) e O Artista (1878-1890).

O recorte temporal elencado data da primeira publicação localizada em 1845 até o ano de 1889; no entanto, as folhas locais continuaram publicando folhetins nas décadas seguintes, mas adotamos o marco histórico - Proclamação da República - como limite porque buscamos analisar as obras dentro de uma mesma conjuntura política e, principalmente, porque a partir da década de 90 as publicações do gênero retomam os clássicos das décadas anteriores.

No período supracitado, 166 folhetins foram publicados em Rio Grande. A análise dos mesmos permite-nos constatar que dos 94 autores cujas obras foram catalogadas, 51 são franceses, 9 brasileiros, 4 portugueses, 1 inglês, 1 espanhol, 1 dinamarquês, 1 estadunidense 
e 25 são de autores desconhecidos, dos quais não localizamos informações e que acreditamos ser, em grande número, pseudônimos.

As décadas de 1850 e 1880 caracterizam-se como ápices de publicações. Na primeira, destacam-se autores como os franceses Eugène Sue, Eugène Scribe, Alexandre Dumas, George Sand, Xavier de Marmier, Frédéric Soulié, os brasileiros Joaquim Manoel de Macedo, Teixeira e Souza, os portugueses José da Silva Mendes Leal e José Joaquim Rodrigues de Bastos, etc. Já na segunda, Xavier de Montépin, Émile Richebourg, Pierre Zaccone, Octave Feuillet, Fortuné du Boisgobey e Jules Mary.

Ao analisar a lista e obras e confrontá-la com a pesquisa de Yasmin Nadaf (2002) e de Ilana Heineberg (2004), percebemos que 36 folhetins publicados em Rio Grande foram anteriormente publicados pelo Jornal do Comércio, no Rio de Janeiro; outras folhas como o Diário do Rio de Janeiro e Correio mercantil também serviram de fonte para a republicação. A equiparação de dados de outras províncias e cidades é salutar porque mostra, por exemplo, a semelhança de títulos com Rio de Janeiro e Mato Grosso (NADAF, 2002); além disso, vinte obras publicadas nas folhas de Rio Grande também o foram em Porto Alegre (HOHLFELDT, 2003, p. 299-310).

Conforme os dados supracitados, os jornais do interior do país valiam-se das traduções da Corte, visto que eram raros os tradutores e altos os custos tanto para a compra do original quanto para o pagamento dos profissionais. Ademais, a demanda por folhetins era grande, visto que, por exemplo, um mesmo número apresentava o último capítulo de uma obra e o primeiro da próxima, como ocorre no Rio-Grandense em 23 de abril de 1851, que 
publica o desfecho de Madelina, de Paulo A. Gustavo, e o princípio de Judith, ou O camarote da ópera, de Eugène Scribe.

O espaço do folhetim também era utilizado para a crítica teatral, escrita pelos jornalistas da província; alguns deles não se identificavam e utilizavam pseudônimos como, por exemplo, "Swift", em referência ao escritor irlandês Jonathan Swift (1667-1745), em crítica à peça Dama das Camélias foi publicada no jornal Diário do Rio Grande, em 29 de abril de 1858, na seção "Revista Teatral”, já que esse drama estava sendo representado no Teatro Sete de Setembro. No Eco do Sul, em 14 de janeiro de 1881, há uma crônica, no rodapé da primeira página do jornal, que trata dos preceitos do teatro intitulada Amável leitor, de Benjamin de Assis.

\section{AS OBRAS “DESCONHECIDAS” LOCALIZADAS:}

Dentre as obras reconhecidas de brasileiros como, por exemplo, as de José de Alencar e Joaquim Manoel de Macedo, localizamos, nos periódicos pesquisados, textos desconhecidos ou que eram considerados "desaparecidos" pela crítica e historiografia literária.

Descreveremos, brevemente, os folhetins: Lúcia de Miranda, de Candido Batista de Oliveira, publicado no jornal Diário do Rio Grande de 18 a 24 de novembro de 1851; Um credor, publicado no jornal Eco do Sul, de 4 de fevereiro a 22 de abril de 1862, tradução de Carlos von Koseritz da novela The Dun (1802), da romancista inglesa Maria de Edgeworth; Um drama no mar, no mesmo jornal, no período de 11 de outubro a 4 de novembro de 1862, com autoria atribuída ao pseudônimo X. Y. Z, que se descobriu ser também de Carlos 
von Koseritz; Dois anjos, do pelotense Juvêncio Menezes Paredes (1833-1882), publicado no jornal Inúbia, nos dias 15, 22 e 29 de março de 1868; A mulher de olhos negros, também de Juvêncio Meneses Paredes, foi publicado de 5 de abril de 1868 até data desconhecida, porque o último número encontrado do periódico era do dia 24 de maio do mesmo ano, os exemplares subsequentes não constam no acervo da Biblioteca Rio-Grandense; Os Mistérios de Rio Grande: a moeda falsa, publicado n'O Tempo, nos dias 5, 11 e 23 de janeiro de 1872, com autoria atribuída ao pseudônimo "Junius"; Tipo de mulher, de Jorge de Andrade, publicado no Diário do Rio Grande, de 19 de junho a 22 de setembro de 1878, no entanto esse texto pode ser de autoria do portoalegrense João Damasceno Vieira Fernandes (1853-1910) reconhecido jornalista, dramaturgo, historiador e poeta, já que no jornal Violeta, as redatoras - Revocata Heloisa de Mello e Julieta de Mello Monteiro - atribuem a autoria dessa obra a ele (SWOBODA, 2017).

Neste artigo centraremos a análise em dois textos: Lúcia de Miranda, de Candido Batista de Oliveira e Um drama no mar, do conhecido jornalista e político alemão radicado no Brasil, Carlos von Koseritz. Obras que julgamos apresentar um tom didático, a primeira informando aos leitores um capítulo da história da Argentina e a segunda abordando acontecimentos reais, ocorridos em alto-mar nas proximidades da cidade de Rio Grande, que espantaram os leitores das folhas locais.

O folhetim Lúcia de Miranda foi apresentando com o subtítulo de "Romance histórico". No periódico não há referência ao nome completo de seu autor, consta apenas as iniciais C.B.O. Entretanto, o gaúcho publicou obra homônima na revista Guanabara, no Rio 
de Janeiro, em 1850, dado que encontramos no folhetim no dia 24 de novembro de 1851 e que pudemos constatar nos acervos da Biblioteca Nacional.

A narrativa baseia-se em acontecimentos históricos que foram anteriormente narrados por Ruy Díaz de Guzmán em seu livro Historia argentina del descubrimiento, población y conquista del Río de la Plata (1612), de acordo com o estudo de Gabriela Nouzeilles e Graciela Montaldo, no livro The Argentina reader: history, culture, politics (2002). As historiadoras evidenciam que o destino de Lúcia de Miranda é um tópico clássico na história colonial: a mulher branca como objeto de negociação e disputa entre duas culturas diferentes. Ao ler a compilação realizada por Patricia Owen Steiner, entendemos que o enredo das narrativas é o mesmo e que, inclusive, a caracterização dos personagens, a sequência das ações, a predominância da voz do narrador em detrimento da dos personagens, são semelhantes.

O narrador de Candido, porém, detalha mais os acontecimentos, acrescentando descrições dos locais, dos sentimentos e dos próprios personagens. Apesar dos índios serem os primitivos que habitavam as proximidades do Prata antes da colonização, Guzmán apresenta uma narração em que os mesmos são vistos como selvagens, enquanto os espanhóis são os heróis corajosos e leais; posicionamento repetido por Oliveira dois séculos depois. Há, em ambos os textos, a exposição da visão do colonizador, do Europeu, em oposição ao ameríndio, ao americano, descrito de maneira negativa.

O folhetim apresenta também seguinte epígrafe: "Ensaio romântico sobre um acontecimento trágico da conquista do rio da prata, oferecido ao instituto histórico pelo seu sócio C.B.O." (OLIVEIRA, 2017, p. 23). Trata-se, então, de uma narrativa histórica que se 
ambienta às margens do Rio da Prata, na expedição comandada pelo navegador Sebastião Caboto (1476-1557) que desviou a sua rota para o Oriente a fim de explorar as riquezas descobertas por D. João Diaz de Solis (1470-1516), em 1514.

A narrativa passa-se no povoado criado pelos espanhóis, no qual erigiram o forte Espírito Santo. O texto narra, inicialmente, a relação amigável entre os espanhóis e os índios Timbús, que tinham como caciques os irmãos Mangoré e Seripó. Por outro lado, há a narração sobre o casal Lúcia de Miranda e Sebastião Furtado: ela um ideal de beleza e formosura e a causadora de todo o conflito, já que Mangoré apaixona-se pela jovem e julga que seus sentimentos são por ela alimentados.

O narrador, apesar de salientar que a mulher incentivou o amor do cacique, atribui o gesto à benevolência da jovem, que era ingênua e estava sendo gentil, o erro de interpretação é relacionado ao índio que, por ser selvagem, entendeu gestos educados, civilizados, como resposta positiva a seu amor. Em consequência disso, o índio tenta, primeiramente, ludibriar o casal convidando-os para passar um tempo em sua tribo, pondo à disposição a sua cabana, convite esse recusado por Furtado que, talvez, tenha compreendido os anseios secretos do cacique.

O pano de fundo histórico apresenta ao leitor a oposição entre o civilizado e o bárbaro (europeu $\mathrm{X}$ índio), sendo os espanhóis as vítimas da vilania dos índios que, por motivos torpes, dizimaram um povoado. O plano de Mangoré é colocado em prática de forma quase infalível: os espanhóis, em menor número devido à ausência de alguns oficiais e em meio ao inesperado ataque, foram alvo fácil e o único empecilho foi astúcia de $D$. Nuno e o duelo que ele travou com o índio, que culminou na morte dos dois oponentes. 
Seripó, também líder da tribo, comove-se com a perda do irmão e com a tristeza de Lúcia ao ver a derrota de seu povo e leva a jovem para a tribo como sua esposa. Em meio a esses fatos, Furtado volta da expedição e, não encontrando o corpo da esposa em meio aos mortos, decide procurá-la. Acaba preso e só não é executado porque ela pede que poupem a vida do marido. O cacique, no entanto, proíbe qualquer contato entre eles; com o passar do tempo os espanhóis reaproximam-se e acabam sendo flagrados pelo chefe da tribo, devido à intriga de uma índia enciumada, descrita pelo narrador de forma inferior em beleza e em caráter.

Ao ver-se traído, o cacique condena o casal à morte e, como pena a Furtado, ordena que Lúcia seja executada na sua presença. A jovem é trazida ao tribunal montado pelos índios e não assume a sua culpa perante o executor que a condena e ordena que ela marche rumo às chamas.

Candido B. de Oliveira traz ao leitor brasileiro uma narrativa que caracteriza o território vizinho, descrevendo um acontecimento histórico que, provavelmente, apesar da proximidade, os leitores ignoravam. O texto pode ser considerado uma versão dos fatos e dos textos que Ihe antecederam e a sua publicação em Rio Grande pode ser devida a seu caráter informativo, já que nos jornais locais existem muitas resenhas, notícias, crônicas sobre o passado histórico de vários países europeus e americanos, o que aponta para um possível interesse do público por essa temática.

A segunda obra a ser analisada neste artigo é Um drama no mar, de Carlos von Koseritz, publicada no jornal Eco do Sul, no período de 11 de outubro a 4 de novembro de 1862, com autoria atribuída, nessa versão, ao pseudônimo X. Y. Z; na edição em livro, 
publicada em 1863, também não há o nome do autor. No entanto, atribuímos a autoria a Carlos von Koseritz por dois motivos: por ele ser um dos colaboradores do jornal e, principalmente, por um anúncio publicado no mesmo jornal, em 18 de abril de 1863, divulgando a venda da novela de mesmo título e com autoria do jornalista.

No último dia de publicação ao folhetim, o jornal publicou anúncio oferecendo assinaturas para a publicação impressa, destacando a reação das pessoas da cidade ao acontecido. Conforme nota ao final dessa segunda edição, a narrativa baseia-se numa tragédia ocorrida em praias gaúchas, no ano de 1862: as ações do personagem Elisandro Moriby foram baseadas nos assassinatos realizados por Ferdinando Petrina e menciona, ainda, a sua execução no dia 30 de dezembro de 1862, fato confirmado por um site em língua inglesa, que esclarece, além da data de execução, o motivo: assassinato em alto-mar.

Outro dado que corrobora a ocorrência verídica desse "drama no mar" é uma justificativa à publicação do folhetim encontrada no jornal Eco do Sul, após a exposição do primeiro capítulo:

Um Drama no Mar - É este o título de uma novela que nos foi oferecida pelo seu autor, com o fim de ser publicada em nossas colunas.

Não lemos senão o princípio que hoje estampamos e por isso nada pode nos acrescentar quanto ao mérito do escrito; julgamos, porém, que ele interessará os nossos leitores, porque the serve de base o horrível acontecimento que há poucos dias se deu bem perto de nossas praias e que tanto impressionou o público do lugar.

Não hesitamos, pois de recomendar ao público a leitura da novela com que fomos obsequiados pelo SR. X. Y. Z. (ECO DO SUL, 11 out. 1862) 
Localizamos também referências aos homicídios nas edições dos dias 9, 10, 11 e 12 de outubro de 1862, nas quais os fatos dessa tragédia são narrados anteriormente à publicação do folhetim, o que evidencia a utilização dos mesmos na construção da trama, como se pode perceber no trecho retirado do Eco do Sul do dia 9 de outubro:

Horrível drama marítimo - Ontem chegou ao nosso porto, algemado e preso, um marinheiro austríaco que cometeu horríveis crimes.

Pertencia à tripulação de um navio inglês que saíra de S. Francisco com carga de madeira para Montevidéu, e no alto mar assassinou, não se sabe ainda porque razões, o capitão do navio, a esposa dele e o piloto.

Achando-se armado com duas pistolas não conseguiu o resto da tripulação prendê-lo incontinente, mas apanhando-o um dia desprevenido ocupando a lavar o sangue de que estava coberto lançaram-se sobre ele e o amarraram.

Não havendo mais piloto a bordo, andou o navio sem rumo nas águas de nossa costa; há dias fez sinal à barca "Aliança” para dar-Ihe um piloto, mas esta passou sem atender o sinal.

Mais felizes foram os abandonados marinheiros para com a barca "Ligeira" que Ihes mandou a bordo o contra mestre o qual os trouxe à barra. (ECO DO SUL, 9 out. 1862 p. 2, grifos nossos)

Os trechos destacados estão presentes no folhetim; apenas os nomes das embarcações citadas são omitidos e, além disso, na narrativa, a trama dá-se rapidamente, o patacho não fica dias à mercê da salvação, pois essa ocorre no mesmo dia da prisão de Elisandro. A nacionalidade do assassino também é distinta, pois na notícia ele é descrito 
como austríaco, enquanto na obra ficcional ele é italiano e a nota ao final do volume não retifica essa informação.

Na edição do jornal do dia 12 de outubro, um dia após a publicação do segundo capítulo, há a menção ao nome do personagem Elisandro de Moriby e não ao do assassino que aparece em nota na segunda edição, como citado anteriormente, o que nos mostra que Koseritz utilizou o nome pelo qual o assassino se identificou e que o seu verdadeiro nome deve ter sido descoberto ao longo do inquérito policial.

O piloto do navio, que na narrativa é denominado apenas L..., conforme informação também do jornal, chamava-se Lipari, e a reprodução dos nomes também se estende ao outro piloto Jones, porém não há nenhuma citação nos jornais ao nome da jovem esposa de Lipari, também assassinada. Essa obra apresenta, então, relação com o fait divers, ou seja, "uma notícia extraordinária, transmitida em forma romanceada, num registro melodramático, que vai fazer concorrência ao folhetim e muitas vezes suplantá-lo nas tiragens" (MEYER, 2005, p. 98).

Entretanto, alguns detalhes dos crimes descritos pelo jornal são tratados de forma distinta na narração, pois a esposa de Lipari não está no local no momento dos homicídios. Ela chega: "ao lugar do sinistro a jovem esposa do capitão, filha de Montevidéu, de 15 anos de idade e casada apenas há 3 meses" e tenta "fugir com o fim de recolher-se ao rancho da proa, ele a alcança em caminho e a derruba com duas facadas no peito". No folhetim, Marília está na câmara e é esfaqueada acidentalmente e não consegue fugir do assassino (ECO DO SUL, 10 out. 1862, p. 1). 
No texto, o narrador faz alusão à veracidade dos fatos, mostrando a proximidade entre realidade e ficção no texto, o que fica evidente no primeiro capítulo da narrativa:

O que vou narrar-vos tem um fundo de verdade; os fatos se deram, e deram-se bem perto de nossas praias (...).

Os fatos são reais; alguns aumentos, algumas liberdades são perdoáveis por certo do escritor, que se vê obrigado a revestir o descarnado esqueleto da horrível realidade, como os ouropéis de fantasia. (...)

Nem tudo quanto vou narrar-vos é constatado pelos fatos, nem tudo é real; muitas vezes abandonarei as rédeas à minha fantasia, mas muitas outras cenas são a fiel pintura do ocorrido, e vós o sabeis. (KOSERITZ, 2013, p. 89)

A obra é composta, então, a partir dos fatos noticiados nos jornais da época, que, entretanto, não divulgam as causas dos crimes, mas que aparecem na trama ficcional, através dos "aumentos" dados aos "mistérios" pelos "ouropeis da fantasia", como nos elucida o narrador no trecho supracitado, pois nesse horripilante drama "houve mistérios ocultos, abismos, que não foi permitido prescrutar ao público, mas que pode o escritor utilizar-se deles para colorir a sua narração" (KOSERITZ, 2013, p. 89).

O folhetim narra o triângulo amoroso entre a jovem Marília, seu esposo L... e Elisandro, que, apaixonado, assedia a mulher, desrespeitando o capitão do navio. Em meio à rejeição e ódio ao homem que pensara em lhe atirar ao mar, Elisandro decide vingar-se e mata L..., Jones (o primeiro piloto) e esfaqueia Marília acidentalmente. Após tomar posse da 
embarcação e render a tripulação, o assassino salva a amada e toma posse da mesma através do estupro.

Essas cenas violentas são seguidas pela bravura da tripulação que rende o homicida e, através da ajuda de embarcação rio-grandina, muda a rota para a Barra de Rio Grande. Marília, viúva e desonrada, suicida-se retirando as ataduras que lhe estancavam a hemorragia, aspecto que é narrado com apelo religioso.

Os três protagonistas são tipificados e apenas cumprem seu papel na visão maniqueísta apresentada pelo narrador, apenas o vilão apresenta uma dualidade porque, apesar da criação que recebera e de seu bom coração, é tomado por uma força demoníaca e assim comete os crimes.

O narrador faz um discurso metaliterário, justificando a mescla de elementos reais (os homicídios em alto-mar) à imaginação que completa as lacunas existentes entre o que todos sabem, o que foi noticiado no jornal, e a motivação para os crimes, oculta, preenchida com a história de amor e ódio, com os preceitos religiosos e com a dramaticidade. Ademais, o tom moralizador da narração adverte os leitores para os perigos de uma vida afastada da religião e da moralidade.

Ao intuito doutrinário, o narrador contrasta um apelo confessional desde o prólogo em que explica a sua escrita, até os momentos em que interage com os leitores tratando de suas experiências enquanto marinheiro, apreciador das tempestades em alto-mar e da grandeza de Deus por ser responsável pela fúria da natureza e que perdeu pessoas, de forma trágica. 
O texto apresenta as características marcantes do gênero: o drama dos personagens é destacado com apelo ao melodrama; a voz do narrador conduz o leitor ao longo de todo o texto "corramos um véu, leitores, sobre essas horríveis cenas, que acompanharam aquela noite de tempestade" (KOSERITZ, 2013, p. 107); seus capítulos são findos em momentos de tensão da narração para aumentar o suspense e provocar a curiosidade pela publicação futura "o assassino de machado em punho com os dentes cerrados e olhar chamejante, resoluto e firme, entra na câmara..." (KOSERITZ, 2013, p. 101).

A obra apresenta-se, então, como a narrativa dos homicídios que assombraram a cidade, acrescida das causas e do detalhamento dos acontecimentos preenchidos pelo trabalho do folhetinista através do que, supostamente, teria ouvido escondido e da sua imaginação.

CONSIDERAÇÕES FINAIS:

A preservação do patrimônio cultural, em destaque a literatura, foco deste artigo, é de suma importância para que as obras escritas no passado sejam conservadas e estejam acessíveis ao público. A pesquisa que apresentamos é um exemplo de que os arquivos, como os da Biblioteca Rio-Grandense, são fundamentais para que a memória literária possa ser resgatada e obras desconhecidas ou perdidas possam ser trazidas à luz e, com isso, possamos compreender o que era lido e os meios pelos quais como a apreciação era realizada.

Os periódicos são uma fonte documental de grande valia para a apreensão de nossa sociedade e dos textos que eram lidos e publicados nas mais variadas províncias do país. Os 
folhetins encetaram no Brasil uma propagação da literatura e, em meio ao acesso facilitado pelo suporte jornal, popularizaram a ficção no Oitocentos. Além disso, a mescla de escritos de autores locais e de estrangeiros auxiliou no desenvolvimento da imprensa, da intelectualidade e das Letras, pois como escreveu Machado de Assis:

O jornal é a verdadeira forma da república do pensamento. É a locomotiva intelectual em viagem para mundos desconhecidos, é a literatura comum, universal, altamente democrática, reproduzida todos os dias, levando em si a frescura das ideias e o fogo das convicções.

O jornal apareceu, trazendo em si o gérmen de uma revolução. (ASSIS, 2011, p. 48)

Dessa forma, ao apresentar os folhetins Lúcia de Miranda, de Candido Batista de Oliveira e Um drama no mar, de Carlos von Koseritz, intelectuais reconhecidos no país cujas obras estavam "desaparecidas", intentamos divulgar esses textos nos meios acadêmicos como parte da memória literária do século XIX e, assim, evidenciar a riqueza documental da biblioteca mais antiga do estado do Rio Grande do Sul. Ademais, a localização de um grande número de folhetins em uma cidade do interior da Província enfatiza que a literatura, no período analisado, não circulava apenas nos grandes centros e aglutinava textos de autores brasileiros e de estrangeiros, principalmente os franceses.

\section{REFERÊNCIAS}

ASSIS, Machado de. O jornal e o Livro. São Paulo: Companhia das Letras, 2011.

CASTRO, Aloísio Arnaldo Nunes de. A trajetória histórica da conservação restauração de acervos em papel no Brasil. Dissertação de Mestrado em História. UFJF, 2008. Disponível em: < http://www.ufjf.br/ppghistoria/files/2009/12/Aloisio_A_N_de_Castro1.pdf>. Acesso: 25 mai. 2018. 
HEINEBERG, Ilana. La suite au prochain numéro: Formation du roman-feuilleton brésilien à partir des quotidiens Jornal do commercio, Diário do Rio de Janeiro et Correio mercantil (1839-1870). Tese de doutorado: Universite De La Sorbonne Nouvelle - Paris III, 2004.

HOHLFELDT, Antonio. Deus escreve direito por linhas tortas: O romance-folhetim dos jornais de Porto Alegre entre 1850-1900. Porto Alegre: EdPUCRS, 2003.

KOSERITZ, Carlos von. Um drama no mar. Eco do Sul. Rio Grande, 11 out. a 4 nov. de 1862.

MEYER, Marlise. Folhetim: uma história. São Paulo: Companhia das letras, 2005.

MONTALDO, Graciela; NOUZEILLES, Gabriela. The Argentina reader: history, culture, politics. Nova York: Duke University Press, 2002.

NADAF, Yasmin Jamil. Rodapé das miscelâneas: o folhetim nos jornais de Mato Grosso, séculos XIX e XX. Rio de Janeiro: 7Letras, 2002.

OLIVEIRA, Candido Batista de. Lucia de Miranda. Diário do Rio Grande, de 18, 19, 24 nov. 1851.

PEREIRA, Fernanda Cheiran. Arquivos, memória e justiça: Gestão documental e preservação de acervos judiciais no Rio Grande do Sul. Disponível em: <http://www.lume.ufrgs.br/handle/10183/31152>. Acesso em: 12 mai. 2018.

RICOEUR, Paul. Do texto à acção: ensaios de hermenêutica II. Porto: RÉS Editora, 1989.

TINHORÃO, José Ramos. Os romances em folhetins no Brasil: de 1830 à atualidade. São Paulo: Duas Cidades, 1994.

VAZ, Artur Emílio Alarcon; MELLO, Juliane Cardozo de. Carlos von Koseritz: novelas. Porto Alegre: Instituto Estadual do Livro: CORAG, 2013.

Artigo recebido em: 31 de maio de 2018. Artigo aprovado em: 29 de agosto de 2018. 